\title{
Experimental and Numerical Study on Cold-formed Steel Built-up Box Beams
}

\author{
Bunya Chea $^{{ }^{*}}$, Taweep Chaisomphob ${ }^{2}$, Wasan Patwichaichote ${ }^{3}$, Eiki Yamaguchi ${ }^{4}$ \\ ${ }^{1}$ Master Student, Department of Civil Engineering and Technology, Sirindhorn International Institute of Technology, \\ Thammasat University, Pathum Thani, Thailand \\ ${ }^{2}$ Associate Professor, Department of Civil Engineering and Technology, Sirindhorn International Institute of \\ Technology, Thammasat University, Pathum Thani, Thailand \\ ${ }^{3}$ PhD Student, Department of Civil Engineering and Technology, Sirindhorn International Institute of Technology, \\ Thammasat University, Pathum Thani, Thailand, and Assistant Professor, Civil Engineering Department, \\ Chulachomklao Royal Military Academy, Nakorn-Nayok, Thailand. \\ ${ }^{4}$ Professor, Department of Civil Engineering, Kyushu Institute of Technology, Kyushu, Japan \\ *Corresponding author: chea.bunya@yahoo.com
}

\begin{abstract}
In this paper, a study of flexural behavior of cold-formed steel built-up box beam which is commonly used in low rise and residential building is presented. Experimental investigation is conducted to understand about the failure mode and the load capacity of the beam in this study. Numerical analysis by using ABAQUS program was performed in order to verify with experimental result. In addition, influence of thickness, connection spacing, and web height and flange width to thickness ratio, affecting load capacity and buckling behavior of the beam, were discussed. The result shows that the finite element analysis can well predict the flexural strength of the beam and the thickness and connection spacing are the key factors to improve load capacity of the beam.
\end{abstract}

Keywords—Buckling, Connection spacing, Finite element analysis, Imperfection.

\section{INTRODUCTION}

$\mathrm{U}$ ntil now, cold-formed steel structural members have a significant growing in using for steel construction. Cold-formed steel sections can be easy subjected to different kind of failure mode because of their thin thickness that makes increasingly interesting in research in recent years.

The recommendation of the current specification of cold-formed steel, such as American Iron and Steel Institute for Design of Cold-Formed Steel Structural Members [1], is that built-up section flexural strength and moment inertia are approximately equal to the sum of each components. However, experimental and numerical study should have been conducted more to justify the above design approximation.

From the past literatures, numerical study of the same type of beam was presented by Tran et al. of cold-formed built-up box beam [2]. ABAQUS program was used to model their built-up box beams. They found that the results from numerical analysis had a good agreement with the experimental results in term of load capacity and failure mode of the beam. Furthermore, it had the different failure mode between numerical and experimental result of the beam built-up with $\mathrm{C} 15024$ connection spacing $L / 3$, local buckling for numerical result and combination of local, torsional, and distortional buckling. The effect of thickness and connection spacing were the further parametric recommended by the authors. In addition, influence of web height and flange width to thickness ratio of built-up box beam had not yet been carried out. Those factors will be discussed in this paper.
Moreover, different kinds of section like C, Box, I, and Double box were studied by Laim et al [3]. In this research, only one connection spacing L/3 was used. ABAQUS program was used to model their beams. For their box section results, the failure mode of distortional buckling and web buckling were found.

In addition, built-up box made of two $\mathrm{C}$ sections with lip and without lip by applying concentric and eccentric loading was studied by Xu et al. [4]. Shell section was used to model their sections. Initial geometry imperfection, and material nonlinearity were considered. Modeling of cold-formed steel members was very sensitive. This was why computational modeling of coldformed steel was studied by Schafer et al. [5] about the factor sensitivities like element and mesh sensitivity.

Furthermore, built-up closed section with intermediate web stiffener was done by Manikandan and Sukumar [6] by using ANSYS program. Their results showed that flange width and depth of intermediate stiffener were the key affecting the strength and buckling behavior of the member. Their finite element analysis can be used for predicting the load capacity.

This research mainly aims to compare the experimental results with the suitable finite element analysis results by using ABAQUS [7] program version 6.14-1. 


\section{METHODOLOGY}

\section{A. Experimental test}

\section{(1). Test setup}

The beam specimens were exposed to four-point loading therefore they had the constant bending moment in the middle of the span. Deflection and strain were studied on section A-A away from mid-span (Fig. 1).

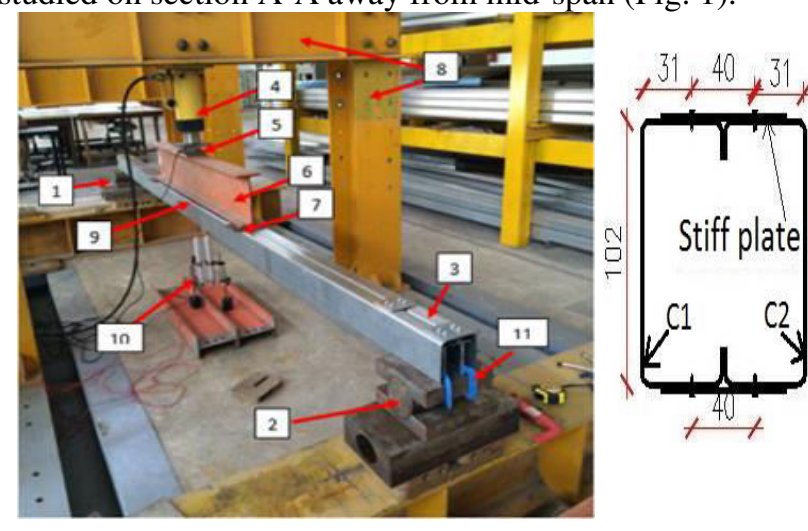

1. Roller support, 2. Pinned support, 3. Beam specimen, 4. Hydraulic jack, 5. Load cell, 6. Load transferring I beam, 7. Bearing plate, 8. Steel frame, 9. Strain gauge, 10. LVDT, 11. Clamp

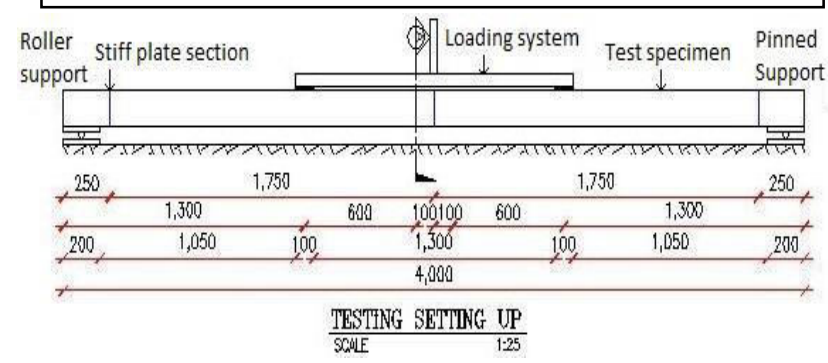

Figure. 1 Built-up box beam test assembly

\section{(2) Test specimens}

There were 16 specimens with four different types of section and four different connection spacing, shown in table 1. Dimension of connection plate is $80 \times 80 \times 2$ $\mathrm{mm}$.

\section{B. Numerical analysis}

\section{(1). Element type}

$\mathrm{C}$ sections and stiffening plates were modeled with shell elements (S4R), which were also used in Schafer's research [5], because of its thin thickness. Based on Kirchoff theory, when one dimension was very small compared with other two dimensions, shell element is recommended. Load bearing plates and support bearing plates were modeled by using solid elements (C3D8R). For screws, function fastener in program Abaqus [7] was used to represent it.

\section{(2). Material properties}

Material nonlinearity (plasticity) was considered for the profile $\mathrm{C}$ sections. Elastic stress-strain was considered for stiffening plate because failure at the stiffening plate was not found. In addition, the material properties for load bearing plates and support bearing plates were assumed as rigid steel with value of thousand time greater than that of normal steel. There were two different types of yield strength and ultimate strength depending on the thickness of the section: $1.2 \mathrm{~mm}$ : Fy= $518.44 \mathrm{MPa}$ and $\mathrm{Fu}=598.65 \mathrm{MPa}$, and $1.5 \mathrm{~mm}$ : $\mathrm{Fy}=$ $522.5 \mathrm{MPa}$ and $\mathrm{Fu}=609.96 \mathrm{MPa}$. Those material properties got from the coupon test. The other properties were young modulus of steel $=208 \mathrm{GPa}$, and Poisson's ratio $=0.3$

\section{(3). Fastener and contact condition}

Since there did not have any failure at the screw connection, function fastener in ABAQUS program [7] was used to represent the screws. In addition, fastener properties were created that all rotational and translational degrees of freedom of the nodes were constrained at the screw location. The radius of the screw was equal to $1.95 \mathrm{~mm}$ and used as the radius dimension in ABAQUS program.

There were contact between two lips of both $\mathrm{C}$ sections, load bearing plate with the beam, and $\mathrm{C}$ sections with the support bearing plate. Surface to surface contact with finite sliding, frictionless, "hard" contact pressure over closure properties was used to represent the interaction between two lips of both $\mathrm{C}$ sections, and load bearing plate with $\mathrm{C}$ sections. Contact between two $\mathrm{C}$ sections and the support bearing plate was tie contact, shown in Fig. 2 (a).

\section{(4). Boundary and loading}

For the test set-up, at both end of the beam specimen, the steel supports were installed. The box beam section was above the steel plate of the support, as shown in Fig. 1. Moreover, steel bearing plate was used in the test to distribute the load from load-transferring I beam to the beam section at two points, as shown in Fig. 1.

On the bottom surface of the support bearing plate, a middle line was drawn in order to specify the conditions of roller and pinned support. At the middle line of bottom surface of the support bearing plate, all translations of the nodes were constrained (X, Y and $\mathrm{Z}$ axis) in order to model as the pinned support, whereas the roller support only the translations in the directions $\mathrm{X}$ and $\mathrm{Y}$ were constrained. Top surface of the load bearing plates was divided into 4 equal areas by drawing the two middle lines of the plate in the direction of the $\mathrm{X}$ and $\mathrm{Z}$ axis. The controlled displacement was subjected vertically with $\mathrm{Y}$ direction on the load bearing plate to simulate the loading on the beam. There were additional restraints in $\mathrm{X}$ and $\mathrm{Z}$ direction located at both ends of the line parallel to $\mathrm{Z}$ axis, as shown in Fig. 2 (c). 
Regional Conference in Civil Engineering (RCCE)

The Third International Conference on Civil Engineering Research (ICCER)

August $1^{\text {st }}-2^{\text {nd }}$ 2017, Surabaya - Indonesia 
Table 1: Type of specimens

\begin{tabular}{|c|c|c|c|c|c|c|c|c|c|c|c|}
\hline $\begin{array}{l}\text { Name of } \\
\text { Specimen }\end{array}$ & $\begin{array}{l}\text { Name of } \\
\text { C section }\end{array}$ & $\begin{array}{c}\mathrm{t} \\
(\mathrm{mm})\end{array}$ & $\begin{array}{c}\mathrm{h} \\
(\mathrm{mm})\end{array}$ & $\begin{array}{c}\mathrm{W} \\
(\mathrm{mm})\end{array}$ & $\begin{array}{c}1 \\
(\mathrm{~mm})\end{array}$ & $\begin{array}{l}\mathrm{rs} \\
(\mathrm{mm})\end{array}$ & $\begin{array}{l}\text { Length } \\
(\mathrm{mm})\end{array}$ & $\begin{array}{l}\text { Span } \\
(\mathrm{mm})\end{array}$ & $\begin{array}{c}\text { Connector } \\
\text { spacing }(\mathrm{mm})\end{array}$ & $\mathrm{h} / \mathrm{t}$ & $\mathrm{w} / \mathrm{t}$ \\
\hline $\begin{array}{l}\text { BBC- } \\
10012\end{array}$ & C10012 & 1.2 & 102 & 51 & 12.5 & 5 & 4000 & 3800 & $\begin{array}{c}583,875, \\
1167,1750\end{array}$ & 85 & 42.5 \\
\hline $\begin{array}{l}\text { BBC- } \\
10015\end{array}$ & C10015 & 1.5 & 102 & 51 & 13.5 & 5 & 4000 & 3800 & $\begin{array}{c}583,875, \\
1167,1750\end{array}$ & 68 & 34 \\
\hline $\begin{array}{l}\text { BBC- } \\
15012\end{array}$ & C15012 & 1.2 & 152 & 64 & 14.5 & 5 & 4000 & 3800 & $\begin{array}{c}583,875, \\
1167,1750\end{array}$ & 126.7 & 53.3 \\
\hline $\begin{array}{l}\text { BBC- } \\
15015\end{array}$ & C15015 & 1.5 & 152 & 64 & 15.5 & 5 & 4000 & 3800 & $\begin{array}{c}583,875, \\
1167,1750\end{array}$ & 101.3 & 43.7 \\
\hline
\end{tabular}

*BBC- : Built-up Box C-; t: thickness of $\mathrm{C}$ section; h: depth of $\mathrm{C}$ section; w: length of flange; 1: lip of the $\mathrm{C}$ section at the end of the flange; rs: radius of the curve connection between web and flange.

\section{(5). Finite element mesh}

Finite element meshes of $7.5 \times 7.5 \mathrm{~mm}$ were applied for mesh of the box sections, and stiffening plates because fine mesh was considered based on the experience of Schafer's finding [5]. The size of solid element for load bearing plate is $7.5 \times 7.5 \times 10 \mathrm{~mm}$. Moreover, the cubic element of $20 \times 20 \times 20 \mathrm{~mm}$ mesh size was implemented for the support plate to save the computational time. For the curve at corner of the $\mathrm{C}$ section and the lip, three divisions was applied in order to get more accurate results that can be seen in Fig. 2 (b).

\section{(6). Analytic procedure}

Each of the model was analyzed in two procedures. Linear buckling analysis was performed to get the buckling shape (eigenvectors). The buckling shape has been used to represent initial imperfection shape with scale factors. Mode 1 in the analysis was taken to be the mode shape. Its thickness of the section was the maximum amplitude or the scale factor of the buckling shape. Then, a general static nonlinear analysis with material nonlinearity and geometry nonlinearity that had initial imperfection shape was conducted in the aim of simulating the structural behavior of cold-formed steel built-up box beam. Function of nonlinear geometry (Nlgeom: On) was opened to deal with nonlinear effects of large displacements.

\section{RESULTS AND DISCUSSION}

Table 2 shows that the different between maximum load from FEA and experiment was between $-14 \%$ and $+12 \%$. For BBC-15012 and BBC-15015, the failure modes getting from FEA and the test were the same with all connection spacing. However, failure mode of BBC-
10012 and BBC-10015 in case of L/6, L/4, and L/2 between FEA and test are similar. In contrast, for these smaller sections in case of connection spacing L/3, FEA results showed that the beams failed in local buckling, but, for the test, it was failed in distortional and local buckling. Load capacity increases when the thickness increases and connection spacing decreases.

A. Key Factors Improving Load Capacity of The Beam

In Fig. 3, the left group of graphs is belong to the specimen with BBC-10012 and BBC-10015 and the right group is belong to the specimen with BBC-15012 and BBC-15015. Each side of the group shows that when web height to thickness ratio decreases, the beam capacities increase remarkably with the both results from experiment and finite element analysis. Therefore, thickness was an essential factor to increase load capacity of the beam because each group of the graph had the same height, but thickness was varied among 1.2, and $1.5 \mathrm{~mm}$. In addition, high web height to thickness ratio of each group of the graph shows the susceptibility to the buckling of the beam. Observing in Fig. 3, the load capacity of the beam increased when the thickness was same and the height of the section was larger. Moreover, while connection spacing was enlarged, the load capacity was reduced. The plot of flange width to thickness ratio was demonstrated in Fig. 4 and the same tendency was confirmed.

\section{B. Load-Deflection Curve}

Figure 5 illustrates that the load deflection curve between experiment and FEA has a good agreement among each other, especially the model with connection spacing L/3. All curves from FEA were matched with the experimental curves. 
August $1^{\text {st }}-2^{\text {nd }}$ 2017, Surabaya - Indonesia

(a)

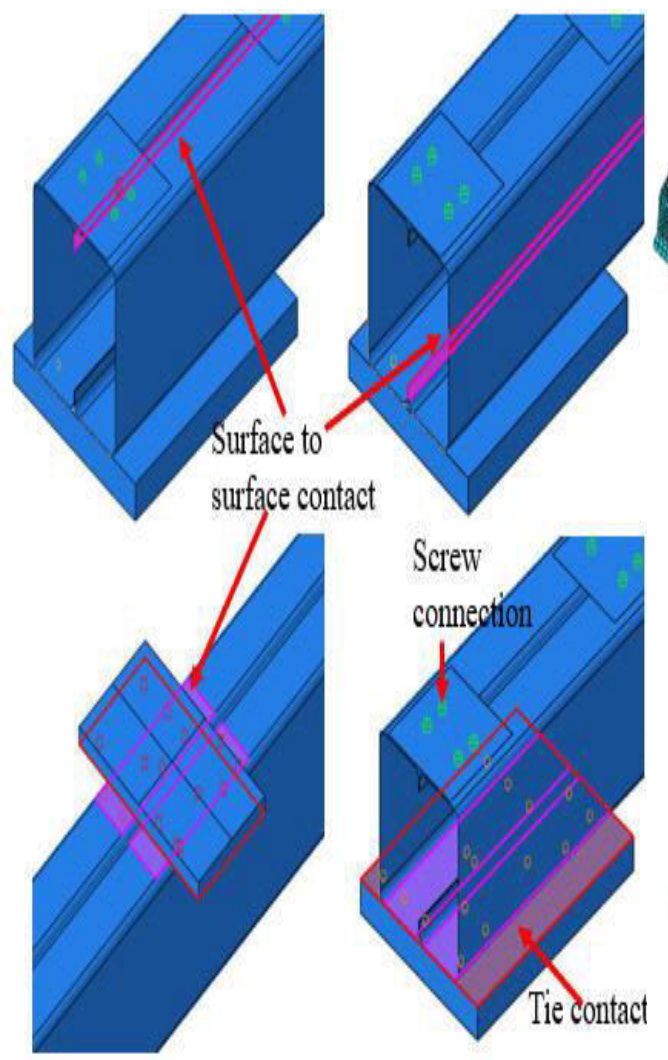

(c)

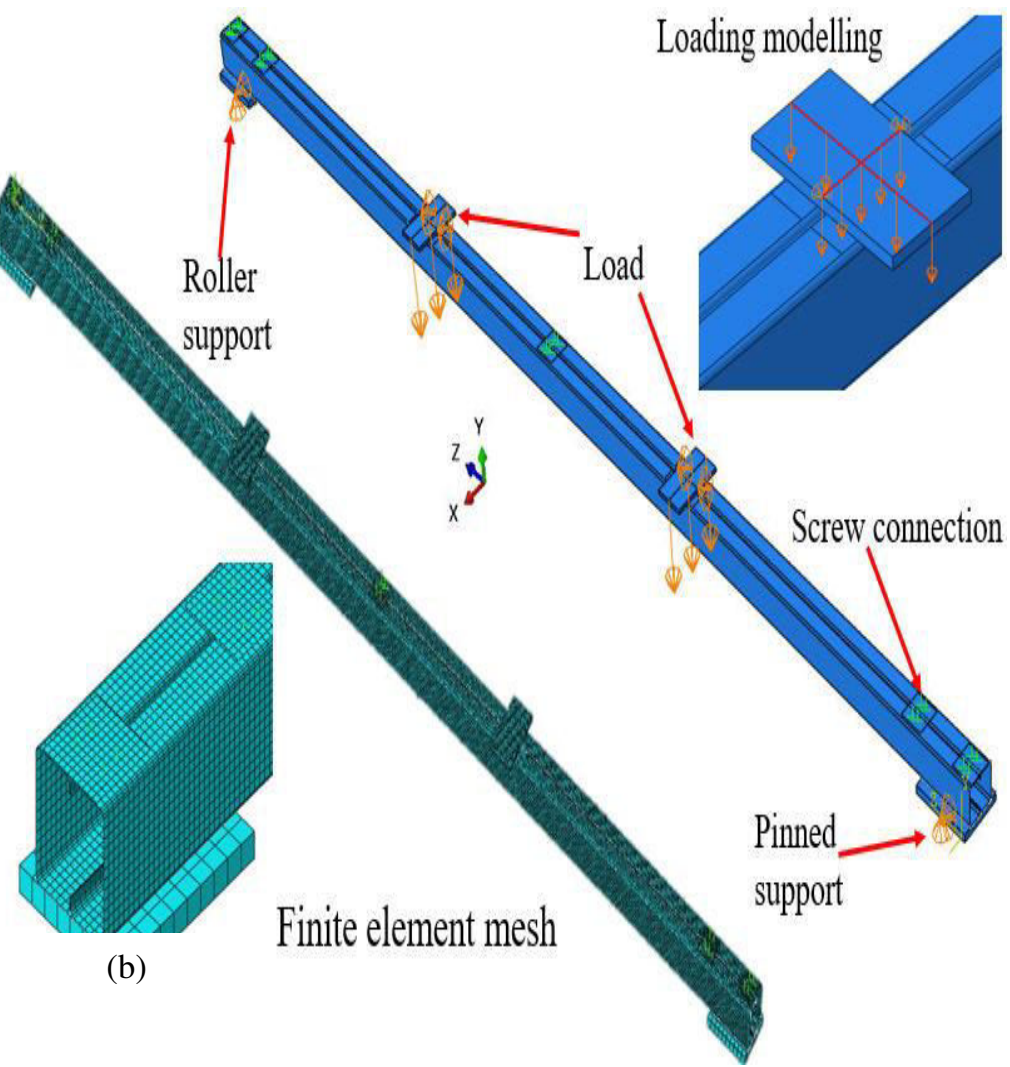

Figure 2: Finite element modeling: (a): contact conditions and screw connections, (b) Finite element mesh, (c) loading and support conditions

Table 2: FEA results and test result

\begin{tabular}{|c|c|c|c|c|c|c|c|c|}
\hline \multirow{3}{*}{ Specimen } & \multirow{3}{*}{$\begin{array}{l}\text { Connection } \\
\text { spacing } \\
\text { (mm) }\end{array}$} & \multicolumn{3}{|c|}{ FEA results } & \multicolumn{3}{|c|}{ Experiment results } & \multirow{3}{*}{$\frac{P_{F E A}}{P_{\max }}$} \\
\hline & & \multirow{2}{*}{$\begin{array}{l}P_{\text {FEA }} \\
(\mathrm{KN})\end{array}$} & \multicolumn{2}{|c|}{ Main failure mode } & \multirow{2}{*}{$\begin{array}{l}\mathrm{P}_{\max } \\
(\mathrm{KN})\end{array}$} & \multicolumn{2}{|c|}{ Main failure mode } & \\
\hline & & & $\mathrm{C}_{1}$ & $\mathrm{C}_{2}$ & & $\mathrm{C}_{1}$ & $\mathrm{C}_{2}$ & \\
\hline \multirow{4}{*}{$\begin{array}{l}\text { BBC- } \\
10012\end{array}$} & $\mathrm{~L} / 6$ & 9.73 & LB & LB & 9.29 & LB & LB & 1.05 \\
\hline & $\mathrm{L} / 4$ & 9.34 & LB & LB & 8.32 & LB & LB & 1.12 \\
\hline & $\mathrm{L} / 3$ & 9.66 & LB & LB & 8.69 & $\mathrm{DB}+\mathrm{LB}$ & $\mathrm{DB}+\mathrm{LB}$ & 1.11 \\
\hline & $\mathrm{L} / 2$ & 8.52 & LTB & $\mathrm{DB}+\mathrm{LB}$ & 8.25 & LTB & $\mathrm{DB}+\mathrm{LB}$ & 1.03 \\
\hline \multirow{4}{*}{$\begin{array}{l}\text { BBC- } \\
10015\end{array}$} & $\mathrm{~L} / 6$ & 13.75 & LB & LB & 15.8 & LB & LB & 0.87 \\
\hline & $\mathrm{L} / 4$ & 13.53 & LB & LB & 15.21 & LB & LB & 0.89 \\
\hline & $L / 3$ & 13.7 & LB & LB & 14.53 & $\mathrm{DB}+\mathrm{LB}$ & $\mathrm{DB}+\mathrm{LB}$ & 0.94 \\
\hline & $\mathrm{L} / 2$ & 12.88 & LTB & $\mathrm{DB}+\mathrm{LB}$ & 11.69 & LTB & $\mathrm{DB}+\mathrm{LB}$ & 1.10 \\
\hline \multirow{4}{*}{$\begin{array}{l}\text { BBC- } \\
15012\end{array}$} & $\mathrm{~L} / 6$ & 15.83 & LB & LB & 17.06 & LB & LB & 0.93 \\
\hline & $\mathrm{L} / 4$ & 15.31 & LB & LB & 14.3 & LB & LB & 1.07 \\
\hline & $\mathrm{L} / 3$ & 15.82 & $\mathrm{DB}+\mathrm{LB}$ & $\mathrm{DB}+\mathrm{LB}$ & 16.28 & $\mathrm{DB}+\mathrm{LB}$ & $\mathrm{DB}+\mathrm{LB}$ & 0.97 \\
\hline & $\mathrm{L} / 2$ & 12.8 & LTB & $\mathrm{DB}+\mathrm{LB}$ & 14.21 & LTB & $\mathrm{DB}+\mathrm{LB}$ & 0.9 \\
\hline \multirow{4}{*}{$\begin{array}{l}\text { BBC- } \\
15015\end{array}$} & $\mathrm{~L} / 6$ & 23.51 & LB & LB & 22.62 & LB & LB & 1.04 \\
\hline & $\mathrm{L} / 4$ & 22.69 & LB & LB & 22.72 & LB & LB & 0.99 \\
\hline & $L / 3$ & 23.5 & $\mathrm{DB}+\mathrm{LB}$ & $\mathrm{DB}+\mathrm{LB}$ & 24.98 & $\mathrm{DB}+\mathrm{LB}$ & $\mathrm{DB}+\mathrm{LB}$ & 0.94 \\
\hline & $\mathrm{L} / 2$ & 19.93 & LTB & $\mathrm{DB}+\mathrm{LB}$ & 23.22 & LTB & $\mathrm{DB}+$ & 36 \\
\hline
\end{tabular}

L: representative span length $(3.5 \mathrm{~m})$; $\mathrm{C}_{1}$ : one $\mathrm{C}$ section side; $\mathrm{C}_{2}$ : another $\mathrm{C}$ section side; LB: local buckling; $\mathrm{DB}$ : distortional buckle; LTB: lateral torsional buckle; L/6, L/4, L/3, and L/2= 583, 875, 1167, and 1750mm respectively. 


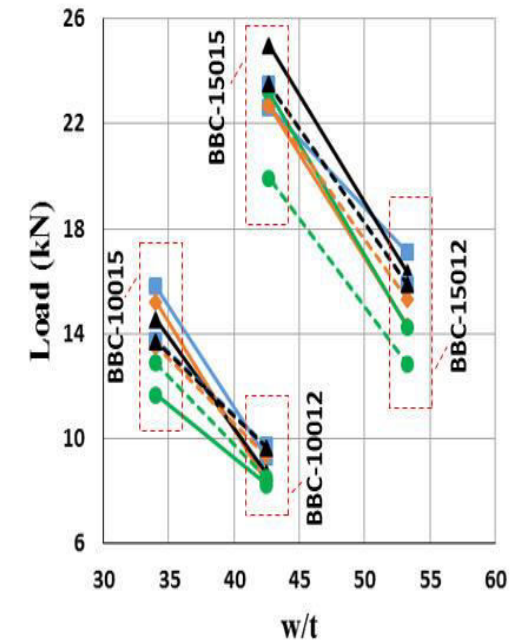

- Experiment L/6

$\longrightarrow$ Experiment L/4

$\leftarrow$ Experiment $\mathrm{L} / 3$

$\multimap$ Experiment L/2

--- FEA L/6

$-\rightarrow-$ FEA L/4

----FEA L/3

- - - FEA L $/ 2$

Fig. 3: Max load-web height to thickness ratio curve for section BBC-100, and BBC-150 having thickness 1.2, and $1.5 \mathrm{~mm}$ with $\mathrm{L} / 6, \mathrm{~L} / 4, \mathrm{~L} / 3$, and $\mathrm{L} / 2$.

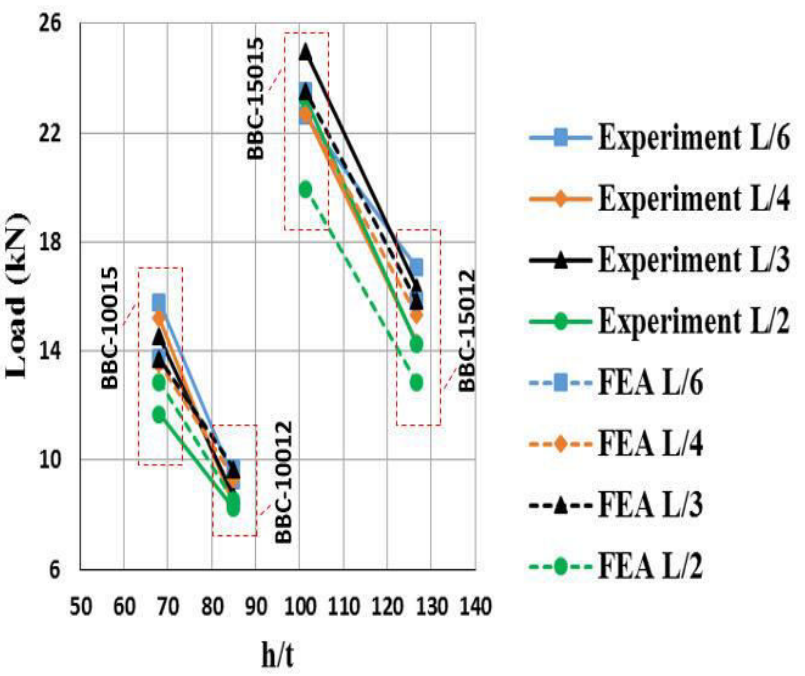

Fig. 4: Max load-flange width to thickness ratio curve for section BBC-100, and BBC-150 having thickness 1.2, and $1.5 \mathrm{~mm}$ with $\mathrm{L} / 6, \mathrm{~L} / 4, \mathrm{~L} / 3$, and $\mathrm{L} / 2$. (a)

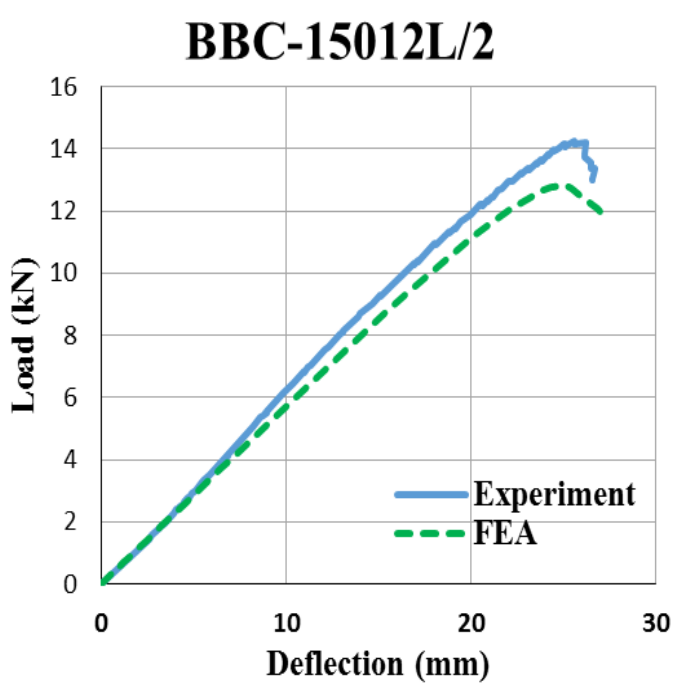

(c)

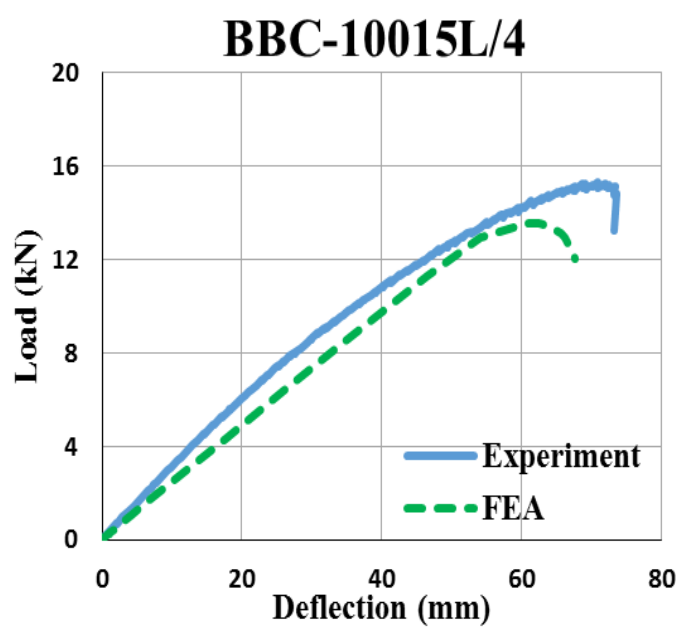

(b)

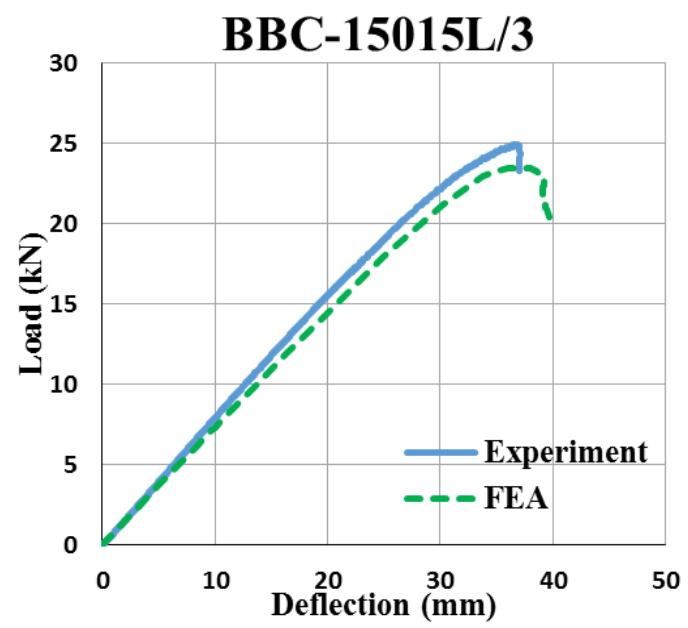

(d)

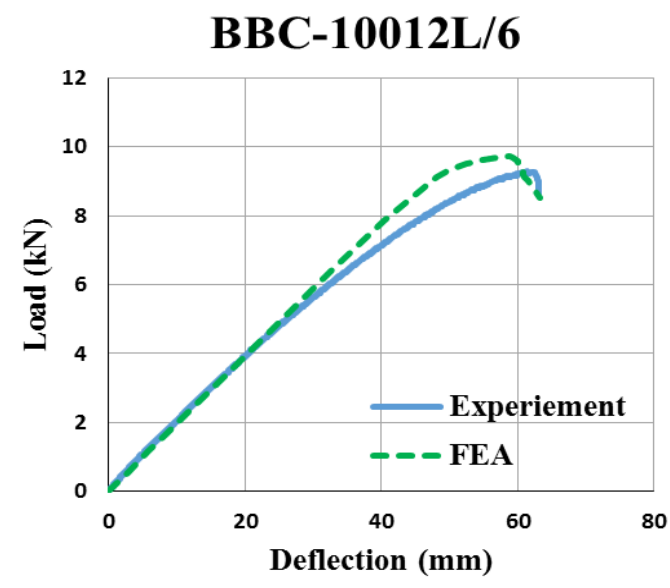

Figure 5: Comparison of load-vertical deflection curve between experimental and FEA results: (a): BBC-15012L/2; (b): BBC-15015L/3; (c): BBC-10015L/4; (d): BBC-10012L/6.

(a) 
The Third International Conference on Civil Engineering Research (ICCER)

August $1^{\text {st }}-2^{\text {nd }} 2017$, Surabaya - Indonesia

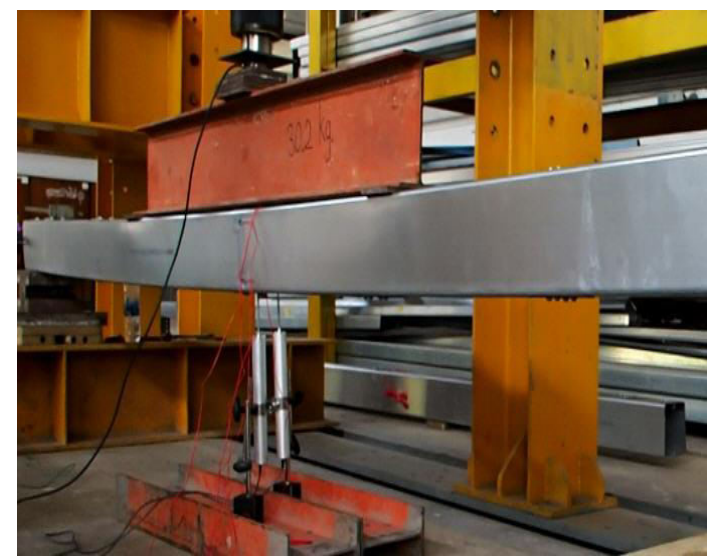

(b)

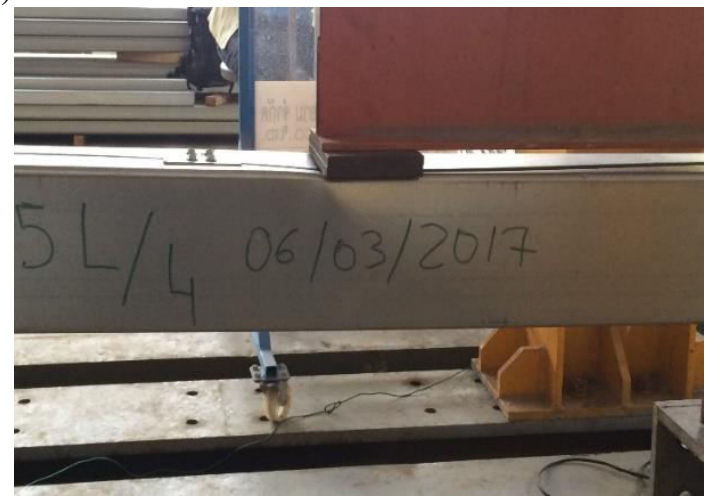

(c)

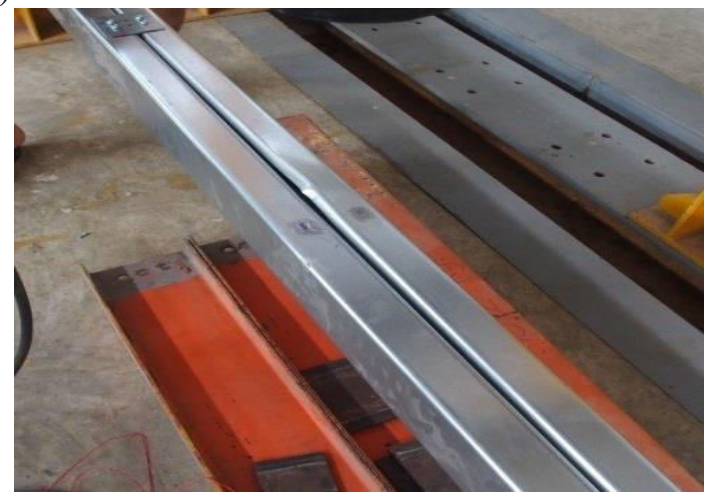

(d)

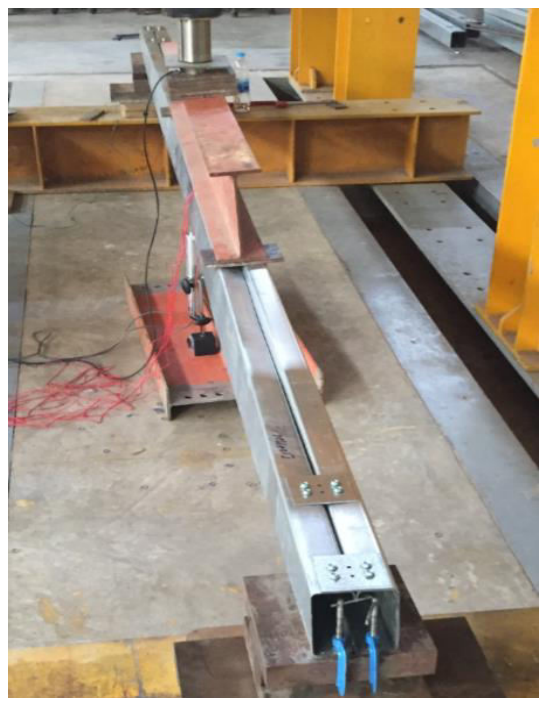

S, Mises

SNEG, (fraction $=-1.0)$

(Avg: 75\%)

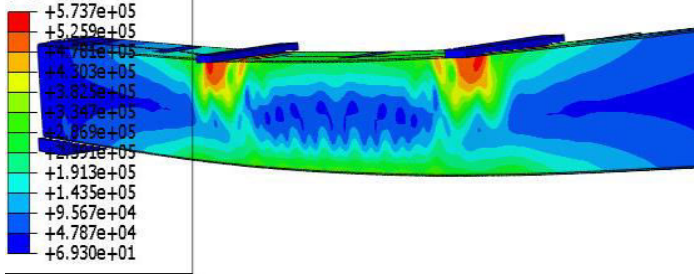
ODB: imperfection.odb Abaqus/Standard 6.14-1 Thu Apr 06 00:45:21 SE Asia
X. Step: Step-1

33: Step Time $=1.000$

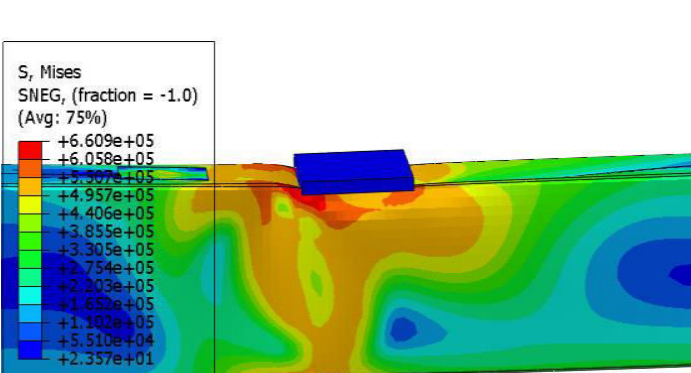

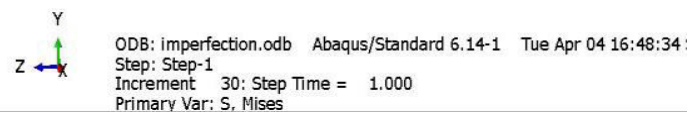
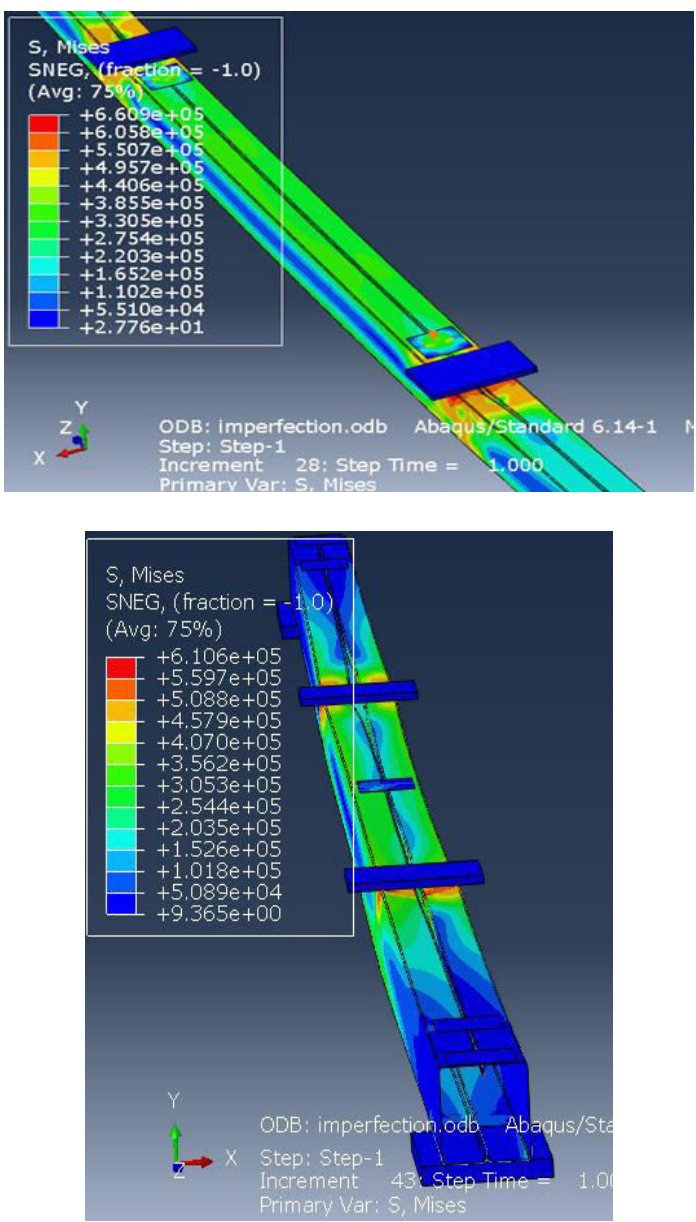

Figure 6: Comparison of failure mode from experiment and finite element analysis: (a): BBC-15012L/6, (b): BBC-15015L/4, (c): BBC-10015L/3, and (d): BBC-10012L/2.

C. Failure Modes

In Fig. 6, failure modes of FEA could be compared with the failure mode of the experiment. For the model with 
connection spacing $\mathrm{L} / 6$ and $\mathrm{L} / 4$, it failed in local buckling similar with experimental results. Moreover, the beam failed in lateral torsional buckling, distortional buckling and local buckling for $L / 2$ similar to experiment. The same failure mode (distortional and local buckling) have been reported for both experimental and FEA results for the larger section BBC-15012L/3 and $\mathrm{BBC}-15015 \mathrm{~L} / 3$. In contrast, it had some differences of failure mode for the smaller section BBC-10012, BBC-10015, and BBC-10019 in case of connection spacing L/3. Distortional buckling has not been found from the finite element analysis results. All details of the failure mode had shown in Table 2.

\section{CONCLUSION}

An experimental and numerical analysis of cold-formed steel built-up box beam was studied with a total of sixteen specimens with four different types of section and four different connection spacing. From the experimental results, the failure modes with connection spacing L/4 or smaller were local buckling, and the failure modes with connection spacing larger than L/4 were mixed modes of local buckling and distortional buckling, or lateral torsional buckling. For the design recommendation, the connection spacing to form the built-up box beam should be the connection spacing L/4 or smaller. The results of finite element analysis and experiment closely matched each other in term of load capacity and failure mode. The different between the maximum load getting from FEA and test was between $14 \%$ and $+12 \%$. Increasing thickness and small connection spacing would increase the flexural capacity of the beam. With the high web height and flange width to thickness ratio, the beams were susceptible to the buckling.

A realistic representation of screws with the 3D element in the finite element model is greatly encourage. In addition, larger sections should be studied. Different span length is another recommendation for further research and the influence of height to span length ratio should be further investigated in order to propose the design method for built-up box section beam that will be very useful in the future.

\section{ACKNOWLEDGEMENT}

The research leading to these results has received the sponsorship of AUN/SEED-Net. The authors would like to gratefully thank for NS BlueScope Lysaght (Thailand) Limited for providing steel materials and acknowledge laboratory of the Chulachomklao Royal Military Academy (CRMA) for providing facilities.

\section{REFERENCES}

[1] AISI, North American Specification for the Design of Cold-Formed Steel Structural Members, S100-12, ed., 2012.

[2] H. Thanh Tran, W. Patwichaichote, T. Chaisomphob and E. Yamaguchi, "Numerical study on flexural behavior of cold-formed steel built-up c section beam", In: The $14^{\text {th }}$ East Asia-Pacific Conference on Structural Engineering and Construction (EASEC-14), Ho Chi Minh City, Vietnam, pp. 1855-1861, 2016.

[3] L. Laim, J. P. C. Rodrigues and L. S. da Silva, "Experimental and numerical analysis on the structural behaviour of cold-formed steel beams", Journal of ThinWalled Structures 72, pp. 1-13, 2013.

[4] L. Xu, P. Sultana and X. Zhou, "Flexural strength of coldformed steel built-up box sections", Journal of Thin-Walled Structures 47, pp. 807-815, 2009.

[5] B. W. Schafer, Z. Li and C. D. Moen, "Computational modeling of Cold-formed steel", Journal of Thin-Walled Structures 48, pp. 752-762, 2010.

[6 P. Manikandan and S. Sukumar, "Behaviour of coldformed steel built-up closed section with intermediate web stiffener under bending", Asian Journal of Civil Engineering (BHRC), Vol. 17, No. 2, pp. 249-257, 2016.

[7] "Simulia. ABAQUS/CAE. Version 6.14-1", Available: http://abaqus.software.polimi.it/v6.14/books/usi/default.ht

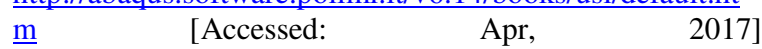

